\title{
T-type $\mathrm{Ca}^{2+}$ channels
}

\section{New players in the aging brain}

\author{
Juliane Proft* and Norbert Weiss* \\ Institute of Organic Chemistry and Biochemistry; Academy of Sciences of the Czech Republic; Prague, Czech Republic
}

Keywords: Alzheimer's disease; Amyloid $\beta$, Calcium signaling, Calcium Channel, T-type channel

*Correspondence to: Juliane Proft and Norbert Weiss; Email: proft@uochb.cas.cz and weiss@uochb.cas.cz

Submitted: 03/02/2014

Accepted: 03/03/2014

Published Online: 03/05/2014

Citation: Proft J, Weiss N. T-type Ca2+ channels: New players in the aging brain. Communicative \& Integrative Biology 2014; 7:e28424; http://dx.doi. org/10.4161/cib.28424

Commentary to: Rice RA, Berchtold NC, Cotman CW, Green KN. Age-related downregulation of the Cav3.1 T-type calcium channel as mediator of amyloid beta production. Neurobiol Aging 2013;35(5): http://dx.doi.org/10.1016/j. neurobiolaging.2013.10.090; PMID:24268883
P erhaps one of the most remarkable features of T-type calcium channels is their low-threshold of activation that makes these channels important candidates for calcium entry near the resting membrane potential of neurons. Hence, they mediate low-threshold burst discharges that occur during different forms of neuronal rhythmogenesis, but play also important roles in sensory transmission, as well as hormone and neurotransmitter release. Additionally, they have been implicated in an increasing number of neuronal pathologies including neuropathy, autism spectrum disorders and some forms of epilepsy. More recently, an implication of T-type calcium channel in the processing of Amyloid Precursor Protein was documented, with possible implication in the pathogenesis of Alzheimer's disease.

Neuronal calcium $\left(\mathrm{Ca}^{2+}\right)$ signaling is of critical importance as it participates in a plethora of cellular processes including membrane excitability, gene expression, synaptic transmission, synaptogenesis, cell death and survival, but also neuronal processes underlying learning and memory. In order to make use and regulate the amplitude, duration and subcellular localization of the $\mathrm{Ca}^{2+}$ signal, cells have developed a complex machinery, the socalled " $\mathrm{Ca}^{2+}$ signaling toolkit," comprised of ion channels, pumps, and exchangers both in the plasma membrane and in the membranes of intercellular organelles (endoplasmic reticulum, mitochondria, Golgi apparatus and nucleus), but also $\mathrm{Ca}^{2+}$ binding proteins and transcriptional factors that altogether coordinate neuronal $\mathrm{Ca}^{2+}$ signaling and homeostasis. ${ }^{1}$ It is thus not surprising that alteration of the $\mathrm{Ca}^{2+}$ signaling machinery, causing either a loss or a gain of function, can lead to serious chronic neuronal disorders. Therefore, despite major intrinsic differences in the pathogenesis of neurodegenerative diseases, alteration in $\mathrm{Ca}^{2+}$ homeostasis has emerged as a common underlying mechanism in Parkinson's disease, Huntington's disease, spinocerebellar ataxias, amyotrophic lateral sclerosis or Alzheimer's disease (AD). Whereas the molecular mechanisms responsible for alterations in neuronal $\mathrm{Ca}^{2+}$ signaling in the aging brain are not clearly understood, numerous studies have reported age-related changes in the expression and/or activity of some of the key players of the $\mathrm{Ca}^{2+}$ machinery, often associated with decreased synaptic plasticity, and in some cases with progressive neuronal loss. Hence, an increased activity of L-type voltage-gated $\mathrm{Ca}^{2+}$ channels has been reported in aged hippocampal neurons. ${ }^{2,3}$ In parallel, elevated intracellular $\mathrm{Ca}^{2+}$ release from the endoplasmic reticulum through ryanodine receptors (RyRs) has been observed, ${ }^{4}$ possibly via enhanced $\mathrm{Ca}^{2+}$-induced $\mathrm{Ca}^{2+}$ release (CICR) as consequence of increased $\mathrm{Ca}^{2+}$ influx through L-type $\mathrm{Ca}^{2+}$ channels. ${ }^{5}$ Additionally, decreased plasma membrane $\mathrm{Ca}^{2+}$-ATPase activity and $\mathrm{Ca}^{2+}$ extrusion, ${ }^{6}$ as well as diminished $\mathrm{Ca}^{2+}$ buffering capacity of the aged neuron (decreased SERCA pump activity ${ }^{7}$ and mitochondrial $\mathrm{Ca}^{2+} \operatorname{sink}^{8}$ have been reported, leading to an overall intracellular free $\mathrm{Ca}^{2+}$ overload. Consistent with the $\mathrm{Ca}^{2+}$ theory of the aging brain, pharmacological regulation of $\mathrm{Ca}^{2+}$ homeostasis using either $\mathrm{Ca}^{2+}$ chelators ${ }^{9}$ or $\mathrm{Ca}^{2+}$ 
channel inhibitors ${ }^{10}$ have shown beneficial effects on age-related cognitive declines. In a recent study published in Neurobiology of Aging, ${ }^{11}$ Rice et $a l$., have examined the possible implication of new $\mathrm{Ca}^{2+}$-related proteins in the aging brain. The results of this study indicate an age-dependent alteration in the expression of $\mathrm{Ca}_{\mathrm{v}} 3.1$ T-type $\mathrm{Ca}^{2+}$ channel. More importantly, the authors demonstrate that T-type $\mathrm{Ca}^{2+}$ channels are functionally coupled to the proteolytic processing of Amyloid Precursor Protein (APP), one of the key suspects in the pathogenesis of Alzheimer's disease. ${ }^{12}$

In a first set of experiments, the authors investigated age-related changes in the expression of some of the $\mathrm{Ca}^{2+}$-related genes. Microarray analysis from human brain samples revealed a significant decrease of about $45 \%$ in the expression of CACNA1G, that encodes the low-voltage-activated $\mathrm{Ca}_{\mathrm{v}} 3.1 \mathrm{~T}$-type $\mathrm{Ca}^{2+}$ channel, in aged non-diseased (74-95) compared with young non-diseased (20-59) individuals. This drop was observed in various brain regions supporting cognitive functions, including the entorhinal cortex, the hippocampus, the posterior cingulate gyrus as well as the superior frontal gyrus. Interestingly enough, a further decrease in $C A C N A 1 G$ expression was observed in $\mathrm{AD}$ aged-patients compared with control aged-individuals in the hippocampus, a region well known to play an important role in the formation of new memories, but also one of the first regions in the brain to suffer damage in AD. Consistent with a drop in CACNA1G expression in the aging brain, western blot analysis of Cav3.1 channel performed on $3 \mathrm{xTg}$ $\mathrm{AD}$ mouse brain (a genetic AD mouse model ${ }^{13}$ ) showed a significant decrease in channel expression with aging. However, a similar decrease in $\mathrm{Ca}_{\mathrm{v}} 3.1$ channel expression was also observed in wild-type animals, suggesting that alteration in $\mathrm{Ca}_{\mathrm{v}} 3.1$ channel expression is mostly related to aging, regardless of the development of AD. In order to evaluate if alteration in Ca 3.1 channel expression observed in the aging brain contributes to the development of $\mathrm{AD}$, the authors analyzed the functional implication of the channel in the processing of that is believed to play a critical role in the pathogenesis of AD. It is well established that proteolytic cleavage of APP by the $\beta$-secretase (also known as $\beta$-site APP cleaving enzyme-1 BACE1) produces a soluble form of APP $\left(\mathrm{sAPP}_{\beta}\right)$ and a 99-amino acid C-terminal fragment (C99) that remains anchored in the plasma membrane. Subsequent processing of C99 by a $\gamma$-secretase generates the socalled amyloid- $\beta$ peptide $(A \beta)$, mainly consisting of a 40-amino acid peptide $\left(\mathrm{A} \beta_{40}\right)$ and the hydrophobe 42 -amino acid product $\left(A \beta_{42}\right)$ that tends to form fibrils, and constitutes the main component of extracellular senile plaques observed in AD brains. In contrast, proteolytic cleavage of APP by the $\alpha$-secretase produces a soluble non-amyloidogenic product $\mathrm{sAPP}_{\alpha}$ with neutrophic effects and promoting synaptogenesis, ${ }^{14}$ and an 83 amino acid C-terminal peptide (C83), precluding the production of $A \beta$. Interestingly, in vivo pharmacological inhibition of T-type $\mathrm{Ca}^{2+}$ channels by intraperitoneal injection of NNC-55-0396 (NNC, a specific T-type channel inhibitor ${ }^{15}$ ) in $14-16$ mo old 3xTg-AD mice produced an increase in soluble $A \beta\left(A \beta_{40}\right.$ and $\left.A \beta_{42}\right)$. However, increased levels of soluble $A \beta_{40}$ and $A \beta_{42}$ were not accompanied by any changes in the number and density of typical senile plaques formed by $A \beta$. It is possible that the relatively short-term application (2 wk) of NNC precludes the formation of new fibrils. Consistent with this idea, a trend to an increased insoluble $A \beta_{42}$ was noticed, suggesting that long-term treatment of $3 x T g-A D$ mice with T-type channel inhibitors could not only produce an increase in soluble $A \beta$ but may also be accompanied by the formation of new senile plaques. Moreover, active $\alpha$-secretase ADAM10 and its proteolytic product C83 were found significantly decreased upon in vivo inhibition of T-type $\mathrm{Ca}^{2+}$ channels. In contrast, immature ADAM10 was found unchanged, suggesting that blocking T-type $\mathrm{Ca}^{2+}$ channels in vivo possibly prevents the maturation of ADAM10 rather than its genic expression. Consistent with in vivo observations, in vitro application of NNC on neuroblaoma cells $\mathrm{N} 2 \mathrm{a}$ reduced expression of active ADAM10 and C83 peptide while soluble $A \beta_{40}$ and $A \beta_{42}$ levels were found increased. In contrast, transient overexpression of $\mathrm{Ca}_{\mathrm{v}} 3.1$ channel in $\mathrm{HEK}$ cells stably expressing APP increased the formation of soluble $\alpha$-APPs suggesting activation of the $\alpha$-secretase pathway. However, in contrast to in vivo observations, only a nonsignificant trend to an increased level of active ADAM10 was observed, questioning the molecular mechanisms by which T-type $\mathrm{Ca}^{2+}$ channels contribute to the processing of APP. Because of the rather depolarized membrane potential of HEK cells (around $-30 \mathrm{mV}$ depending on the culture conditions), T-type $\mathrm{Ca}^{2+}$ channels are mostly inactivated and their contribution in any $\mathrm{Ca}^{2+}$-dependent processes at rest is rather unlikely. The same applies to neuroblastoma cells. Besides the fact that it remains unclear if T-type $\mathrm{Ca}^{2+}$ channels are functionally expressed in N2a cells, ${ }^{16,17}$ it is unlikely that undifferentiated cells can generate electrical activity required for T-type $\mathrm{Ca}^{2+}$ channel activation. Further investigations will certainly identify the precise molecular mechanisms by which T-type $\mathrm{Ca}^{2+}$ channels contribute to the processing of APP. (Fig. 1)

In summary, Rice et al. documented for the first time an age-dependent decrease in $\mathrm{Ca}_{\mathrm{v}} 3.1$ T-type $\mathrm{Ca}^{2+}$ channel expression, extending the growing list of $\mathrm{Ca}^{2+}$-dependent proteins possibly involved in the aging brain. More importantly, they provided evidence for a functional implication of T-type $\mathrm{Ca}^{2+}$ channels in the proteolytic processing of APP where proper channel activity is required for non-amyloidogenic processing of APP, precluding the production of $A \beta$ and possibly associated senile plaques. Interestingly, a recent study documented an increase in insoluble $\mathrm{A} \beta_{42}$ production in the aging brain. ${ }^{18}$ The age-dependent alteration in $\mathrm{Ca}_{\mathrm{v}} 3.1 \mathrm{~T}$-type $\mathrm{Ca}^{2+}$ channel expression observed by Rice et al. could certainly contribute to the changes in APP processing with aging and possibly contribute to the pathogenesis of AD. Moreover, considering the critical role of T-type $\mathrm{Ca}^{2+}$ channels in supporting physiological functions as learning and memory, ${ }^{19}$ it is conceivable that alteration in channel activity could participate in the cognitive declines associated with the aging brain. It thus appears that pharmacological activation of T-type $\mathrm{Ca}^{2+}$ channels could represent a promising therapeutic strategy to prevent and/or reverse age-dependent cognitive declines, and possibly to preclude the formation of 


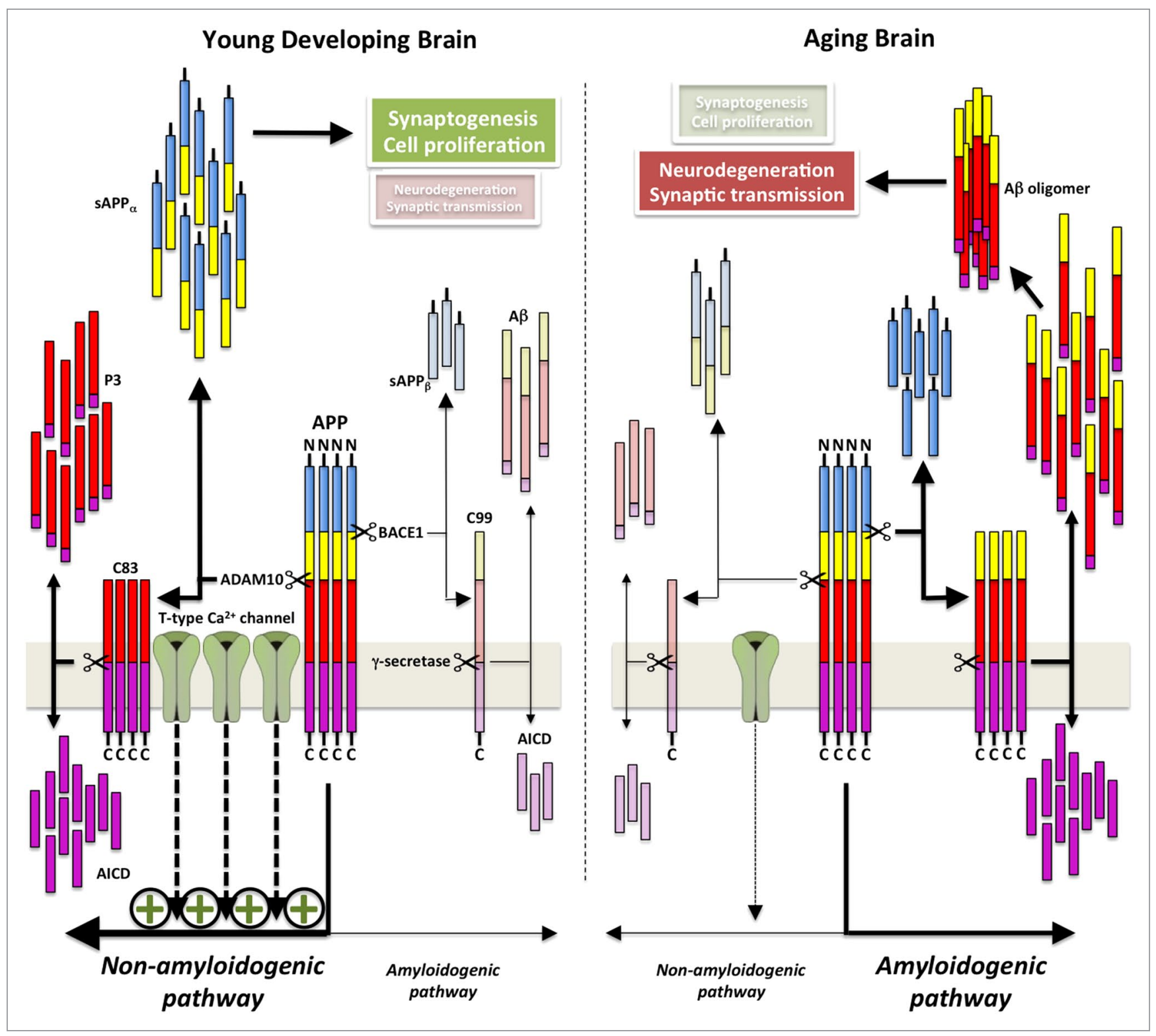

Figure 1. A putative model of functional coupling between T-type $\mathrm{Ca}^{2+}$ channels and APP processing. The amyloidogenic pathway is characterized by the proteolytic cleavage of APP by $\beta$-secretase (BACE1) and the resulting production of a soluble APP fragment (SAPP $)$ and a 99 -amino acid C-terminal fragment (C99) that is subsequently processed by $\gamma$-secretase to generate neurotoxic $A \beta\left(A \beta_{40}\right.$ and $A \beta_{42}$ ) peptides that tend to aggregate and form extracellular senile plaques. In contrast, the non-amyloidogenic processing of APP by $\alpha$-secretase (ADAM10) produces an 83-amino acid C-terminal fragment (C83) precluding the formation of APP, and a soluble SAPP ${ }_{\alpha}$ product with neurotrophic effects that counteract apoptotic signaling and promote synaptogenesis. In the young developing brain, activation of T-type $\mathrm{Ca}^{2+}$ channels stimulates non-amyloidogenic processing of APP, possibly by facilitating the maturation of ADAM10, which supports neuronal growth and synaptogenesis. In contrast, alteration of T-type $\mathrm{Ca}^{2+}$ channel expression in the aging brain favors amyloidogenic processing of APP and associated neuronal damages.

$A \beta$ senile plaques that is still considered as one of the main hypothesis of $\mathrm{AD}^{20,21}$ Consistent with this idea, it was recently shown that T-type $\mathrm{Ca}^{2+}$ channels are the pharmacological targets of the cognitive enhancer ST 101. ${ }^{17}$ In contrast, pharmacological inhibition of T-type $\mathrm{Ca}^{2+}$ channels has recently emerged as a promising therapeutic strategy for the treatment of some forms of epilepsy, ${ }^{22}$ as well as for the management of neuropathic pain. ${ }^{23,24}$ Hence, if the development of new T-type $\mathrm{Ca}^{2+}$ channel modulators is emerging as especially attractive therapeutic strategy for the treatment of various neurological disorders, their general use in clinic has to be cautious to not face the Jekyll and Hide syndrome of T-type channels like it has been shown for $\mathrm{A} \beta .^{25}$
Disclosure of Potential Conflicts of Interest

No potential conflicts of interest were disclosed.

\section{Acknowledgments}

J.P. is supported by a postdoctoral fellowship from the Institute of Organic Chemistry and Biochemistry and the Academy of Sciences of the Czech Republic. 


\section{References}

1. Brini M, Calì T, Ottolini D, Carafoli E. Neuronal calcium signaling: function and dysfunction. Cell Mol Life Sci 2014; PMID:24442513; http://dx.doi. org/10.1007/s00018-013-1550-7

2. Porter NM, Thibault O, Thibault V, Chen KC, Landfield PW. Calcium channel density and hippocampal cell death with age in long-term culture. J Neurosci 1997; 17:5629-39; PMID:9204944

3. Thibault O, Hadley R, Landfield PW. Elevated postsynaptic $[\mathrm{Ca} 2+] \mathrm{i}$ and L-type calcium channel activity in aged hippocampal neurons: relationship to impaired synaptic plasticity. J Neurosci 2001; 21:9744-56; PMID:11739583

4. Liu J, Supnet C, Sun S, Zhang H, Good L, Popugaeva E, Bezprozvanny I. The role of ryanodine receptor type 3 in a mouse model of Alzheimer disease. Channels (Austin) 2014; 8:8(3); PMID:24476841; http://dx.doi.org/10.4161/chan.27471

5. Gant JC, Sama MM, Landfield PW, Thibault O. Early and simultaneous emergence of multiple hippocampal biomarkers of aging is mediated by $\mathrm{Ca} 2+$-induced $\mathrm{Ca} 2+$ release. J Neurosci 2006; 26:3482-90; PMID:16571755; http://dx.doi. org/10.1523/JNEUROSCI.4171-05.2006

6. Michaelis ML, Bigelow DJ, Schöneich C, Williams TD, Ramonda L, Yin D, Hühmer AF, Yao Y, Gao J, Squier TC. Decreased plasma membrane calcium transport activity in aging brain. Life Sci 1996; 59:405-12; PMID:8761328; http://dx.doi. org/10.1016/0024-3205(96)00319-0

7. Murchison D, Griffith WH. Age-related alterations in caffeine-sensitive calcium stores and mitochondrial buffering in rat basal forebrain. Cell Calcium 1999; 25:439-52; PMID:10579055; http://dx.doi. org/10.1054/ceca.1999.0048

8. Murchison D, Zawieja DC, Griffith WH. Reduced mitochondrial buffering of voltage-gated calcium influx in aged rat basal forebrain neurons. Cell Calcium 2004; 36:61-75; PMID:15126057; http:// dx.doi.org/10.1016/j.ceca.2003.11.010

9. Tonkikh AA, Carlen PL. Impaired presynaptic cytosolic and mitochondrial calcium dynamics in aged compared to young adult hippocampal CA1 synapses ameliorated by calcium chelation. Neuroscience 2009; 159:1300-8; PMID:19215725; http://dx.doi. org/10.1016/j.neuroscience.2008.12.057
10. Tollefson GD. Short-term effects of the calcium channel blocker nimodipine (Bay-e-9736) in the management of primary degenerative dementia. Biol Psychiatry 1990; 27:1133-42; PMID:2187540; http:// dx.doi.org/10.1016/0006-3223(90)90050-C

11. Rice RA, Berchtold NC, Cotman CW, Green $\mathrm{KN}$. Age-related downregulation of the CaV3.1 T-type calcium channel as a mediator of amyloid beta production. Neurobiol Aging 2014; 35:1002 11; PMID:24268883; http://dx.doi.org/10.1016/j. neurobiolaging.2013.10.090

12. Proft J, Weiss N. A protective mutation against Alzheimer disease? Commun Integr Biol 2012; 5:3013; PMID:23060947; http://dx.doi.org/10.4161/ cib. 21799

13. Götz J, Ittner LM. Animal models of Alzheimer's disease and frontotemporal dementia. Nat Rev Neurosci 2008; 9:532-44; PMID:18568014; http://dx.doi. org/10.1038/nrn 2420

14. Bell KF, Ducatenzeiler A, Ribeiro-da-Silva A, Duff K, Bennett DA, Cuello AC. The amyloid pathology progresses in a neurotransmitter-specific manner. Neurobiol Aging 2006; 27:1644-57; PMID:16271419; http://dx.doi. org/10.1016/j.neurobiolaging.2005.09.034

15. Huang L, Keyser BM, Tagmose TM, Hansen JB, Taylor JT, Zhuang H, Zhang M, Ragsdale DS, Li M. NNC 55-0396 [(1S,2S)-2-(2-(N-[(3-benzimidazol-2-yl) propyl]-N-methylamino)ethyl)-6-fluoro-1,2,3,4-tetrahydro-1-isopropyl-2-naphtyl cyclopropanecarboxylate dihydrochloride]: a new selective inhibito of T-type calcium channels. J Pharmacol Exp Ther 2004; 309:193-9; PMID:14718587; http://dx.doi. org/10.1124/jpet.103.060814

16. Leung YM, Kuo YH, Chao CC, Tsou YH, Chou $\mathrm{CH}$, Lin $\mathrm{CH}$, Wong KL. Osthol is a use-dependent blocker of voltage-gated $\mathrm{Na}+$ channels in mouse neuroblastoma N2A cells. Planta Med 2010; 76:34-40; PMID:19639537; http://dx.doi. org/10.1055/s-0029-1185941

17. Moriguchi S, Shioda N, Yamamoto Y, Tagashira H, Fukunaga K. The T-type voltage-gated calcium channel as a molecular target of the novel cognitive enhancer ST101: enhancement of long-term potentiation and CaMKII autophosphorylation in rat cortical slices. J Neurochem 2012; 121:44-53; PMID:22251222; http://dx.doi.org/10.1111/j.1471-4159.2012.07667.x
18. Miners JS, Jones R, Love S. Differential Changes in $A \beta 42$ and $A \beta 40$ with Age. J Alzheimers Dis 2014; PMID:24503618

19. Chen CC, Greene E, Bowers SR, Mellone BG. A role for the CAL1-partner Modulo in centromere integrity and accurate chromosome segregation in Drosophila. PLoS One 2012; 7:e45094; PMID:23028777; http:// dx.doi.org/10.1371/journal.pone.0045094

20. Tiraboschi P, Hansen LA, Thal LJ, Corey-Bloom $\mathrm{J}$. The importance of neuritic plaques and tangles to the development and evolution of AD. Neurology 2004; 62:1984-9; PMID:15184601; http://dx.doi. org/10.1212/01.WNL.0000129697.01779.0A

21. Bouras C, Hof PR, Giannakopoulos P, Michel JP, Morrison JH. Regional distribution of neurofibril lary tangles and senile plaques in the cerebral cortex of elderly patients: a quantitative evaluation of a one-yea autopsy population from a geriatric hospital. Cereb Cortex 1994; 4:138-50; PMID:8038565; http:// dx.doi.org/10.1093/cercor/4.2.138

22. Powell KL, Cain SM, Snutch TP, O'Brien TJ. Low Threshold T-type Calcium Channels as Targets for Novel Epilepsy Treatments. Br J Clin Pharmacol 2013; PMID:23834404; http://dx.doi.org/10.1111/ bcp. 12205

23. Todorovic SM, Jevtovic-Todorovic V. Neuropathic pain: role for presynaptic T-type channels in nociceptive signaling. Pflugers Arch 2013; 465:9217; PMID:23322114; http://dx.doi.org/10.1007/ s00424-012-1211-y

24. Waxman SG, Zamponi GW. Regulating excitability of peripheral afferents: emerging ion channel targets. Nat Neurosci 2014; 17:153-63; PMID:24473263; http:// dx.doi.org/10.1038/nn.3602

25. Proft J, Weiss N. Jekyll and Hide: The two faces of amyloid $\beta$. Commun Integr Biol 2012; 5:4057; PMID:23181153; http://dx.doi.org/10.4161/ cib. 22571 